University of Nebraska - Lincoln

DigitalCommons@University of Nebraska - Lincoln

Michigan Bovine Tuberculosis Bibliography and

Database

Wildlife Disease and Zoonotics

2005

\title{
Hidden Effects of Chronic Tuberculosis in African Buffalo
}

Anna E. Jolles

Princeton University, Princeton, New Jersey

David V. Cooper

KwaZulu-Natal Wildlife, P.O. Box 25, Mtubatuba 3935, South Africa

Simon A. Levin

Princeton University, Princeton, New Jersey

Follow this and additional works at: https://digitalcommons.unl.edu/michbovinetb

Part of the Veterinary Medicine Commons

Jolles, Anna E.; Cooper, David V.; and Levin, Simon A., "Hidden Effects of Chronic Tuberculosis in African Buffalo" (2005). Michigan Bovine Tuberculosis Bibliography and Database. 56.

https://digitalcommons.unl.edu/michbovinetb/56

This Article is brought to you for free and open access by the Wildlife Disease and Zoonotics at DigitalCommons@University of Nebraska - Lincoln. It has been accepted for inclusion in Michigan Bovine Tuberculosis Bibliography and Database by an authorized administrator of DigitalCommons@University of Nebraska Lincoln. 


\title{
HIDDEN EFFECTS OF CHRONIC TUBERCULOSIS IN AFRICAN BUFFALO
}

\author{
Anna E. Jolles, ${ }^{1,3}$ David V. Cooper, ${ }^{2}$ And Simon A. Levin ${ }^{1}$ \\ ${ }^{1}$ Department of Ecology and Evolutionary Biology, Princeton University, Princeton, New Jersey 08544 USA \\ ${ }^{2}$ KwaZulu-Natal Wildife, P.O. Box 25, Mtubatuba 3935, South Africa
}

\begin{abstract}
Infectious diseases can bring about population declines and local host extinctions, contributing significantly to the global biodiversity crisis. Nonetheless, studies measuring population-level effects of pathogens in wild host populations are rare, and taxonomically biased toward avian hosts and macroparasitic infections. We investigated the effects of bovine tuberculosis (bTB), caused by the bacterial pathogen Mycobacterium bovis, on African buffalo (Syncerus caffer) at Hluhluwe-iMfolozi Park, South Africa. We tested 1180 buffalo for bTB infection between May 2000 and November 2001. Most infections were mild, confirming the chronic nature of the disease in buffalo. However, our data indicate that bTB affects both adult survival and fecundity. Using an age-structured population model, we demonstrate that the pathogen can reduce population growth rate drastically; yet its effects appear difficult to detect at the population level: bTB causes no conspicuous mass mortalities or fast population declines, nor does it alter host-population age structure significantly. Our models suggest that this syndrome-low detectability coupled with severe impacts on population growth rate and, therefore, resilience-may be characteristic of chronic diseases in large mammals.
\end{abstract}

Key words: African buffalo; chronic disease; fecundity; mortality; Mycobacterium bovis; population age structure; population growth rate; population resilience; Syncerus caffer; tuberculosis.

\section{INTRODUCTION}

Emerging infections, involving novel pathogens or bringing established pathogens in contact with naïve host populations, can have drastic effects on their hosts (Daszak et al. 2000, Harvell et al. 2002, Altizer et al. 2003). In addition, pathogens capable of infecting multiple species may cause extinctions, as more-resistant host species act as reservoirs of infection, preventing the demise of the pathogen along with its susceptible hosts (Gog et al. 2002). Despite growing concern over the impact of diseases on wildlife conservation, population-level effects of pathogens in wild host populations have rarely been measured (Gulland 1995, Harvell et al. 1999), and most studies have focused on avian hosts and macroparasitic infections (Tompkins et al. 2002; but see Albon et al. 2002). Further, most wildlife-disease studies focus on catastrophic declines, often of endangered host populations, due to epidemic disease (e.g., Van Riper et al. 1986, Thorne and Wil-

Manuscript received 11 January 2005; revised 21 March 2005; accepted 24 March 2005. Corresponding Editor: K. Wilson.

${ }^{3}$ Present addresses: Community and Conservation Ecology Group, University of Groningen, Groningen, The Netherlands, and Department of Zoology, Oregon State University, Corvallis, Oregon 97331 USA.

E-mail: jollesa@science.oregonstate.edu liams 1988, Berger et al. 1998), while the populationlevel effects of less conspicuous, chronic diseases remain largely obscure.

Mycobacterium bovis causes chronic infection in a wide range of mammalian hosts. The pathogen is exotic to sub-Saharan Africa, and bovine tuberculosis (bTB) is emerging as a wildlife disease in southern Africa (de Lisle et al. 2002). Studies of bTB in wildlife have concentrated on badgers (Meles meles) in the United Kingdom (e.g., Tuyttens et al. 2000, Garnett et al. 2002, Donnelly et al. 2003), and brushtail possums (Trichosurus vulpecula) in New Zealand (e.g., Fulford et al. 2002, Ramsey et al. 2002, Caley and Hone 2004), due to their function as reservoirs of infection for livestock. These studies have yielded detailed information on the effects of bTB on badger and possum behavior and ecology. Such information is much sparser for freeroaming ungulate populations (but see Rodwell et al. 2001).

Our research was conducted at Hluhluwe-iMfolozi Park (HiP), South Africa, where bTB was first diagnosed in 1986 in a buffalo. The park has a buffalo population of approximately 3000 individuals, which appear to be the primary maintenance host for bTB. Park management have maintained an active bTB control program since 1999, which involves annual buffalo 

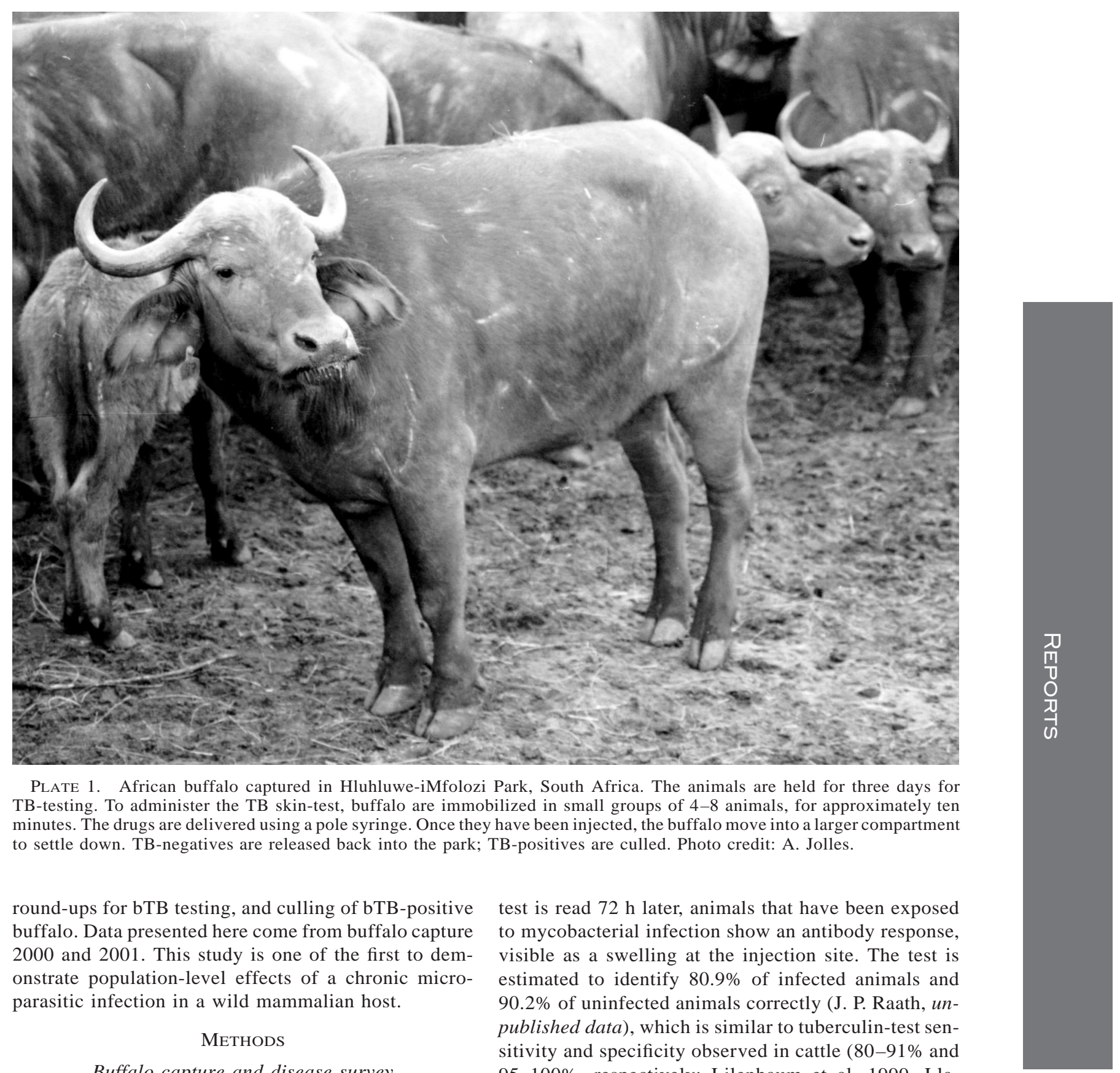

Plate 1. African buffalo captured in Hluhluwe-iMfolozi Park, South Africa. The animals are held for three days for
TB-testing. To administer the TB skin-test, buffalo are immobilized in small groups of $4-8$ animals, for approximately ten minutes. The drugs are delivered using a pole syringe. Once they have been injected, the buffalo move into a larger compartment to settle down. TB-negatives are released back into the park; TB-positives are culled. Photo credit: A. Jolles.

round-ups for bTB testing, and culling of bTB-positive buffalo. Data presented here come from buffalo capture 2000 and 2001. This study is one of the first to demonstrate population-level effects of a chronic microparasitic infection in a wild mammalian host.

\section{METHODS}

\section{Buffalo capture and disease survey}

Buffalo capture and TB testing were conducted by KwaZulu-Natal Wildlife, the organization managing HiP (Hluhluwe-iMfolozi Park, South Africa; see Plate 1). Buffalo herds were chased into a capture corral set up within the park, using a helicopter. All captured animals were marked with brands to allow identification of recaptured animals in subsequent years. Buffalo were tested for TB using a skin test similar to that used to diagnose TB in humans. A small amount of mycobacterial protein (tuberculin) is injected subcutaneously in the buffalo's neck, and the thickness of the skin fold around the injection site is measured. When the test is read $72 \mathrm{~h}$ later, animals that have been exposed to mycobacterial infection show an antibody response, visible as a swelling at the injection site. The test is estimated to identify $80.9 \%$ of infected animals and $90.2 \%$ of uninfected animals correctly (J. P. Raath, unpublished data), which is similar to tuberculin-test sensitivity and specificity observed in cattle (80-91\% and 95-100\%, respectively; Lilenbaum et al. 1999, Llamazares et al. 1999, Ameni et al. 2000). Cross-reactivity of bovine tuberculin with immune responses to other mycobacteria, such as Mycobacterium avium, can yield false-positive results. To identify these cases and thus improve test specificity, we injected buffalo with avian tuberculin on the other side of their necks and considered weak reactions to bovine tuberculin in combination with strong reactions to avian tuberculin to indicate bTB (bovine tuberculosis) negative status. All TB testing was conducted by park and state veterinarians. TB-positive buffalo were slaughtered; negatives were released back into the park. 
TABLE 1. Buffalo vital rates and elasticities of population growth rate $\lambda$ to each parameter.

\begin{tabular}{|c|c|c|c|c|}
\hline Parameter & $\begin{array}{l}\text { Healthy } \\
\text { value }\end{array}$ & $\begin{array}{c}\text { TB- } \\
\text { infected } \\
\text { value }\end{array}$ & $\begin{array}{l}\text { Elasticity } \\
\quad \text { of } \lambda\end{array}$ & Explanation \\
\hline \multicolumn{5}{|l|}{ Fecundity } \\
\hline Subadult & 0.15 & 0.11 & 0.0043 & $\begin{array}{l}\text { annual likelihood that a female buffalo aged } 4.5-5.5 \text { yr bears a fe- } \\
\text { male calf }\end{array}$ \\
\hline Young adult & 0.37 & 0.37 & 0.0243 & $\begin{array}{l}\text { annual likelihood that a female buffalo aged } 5.5-8.5 \text { yr bears a fe- } \\
\text { male calf }\end{array}$ \\
\hline Mature adult & 0.37 & 0.27 & 0.0487 & $\begin{array}{l}\text { annual likelihood that a female buffalo aged } 8.5-15.5 \text { yr bears a fe- } \\
\text { male calf }\end{array}$ \\
\hline Senescent & 0.30 & 0.22 & 0.0138 & $\begin{array}{l}\text { annual likelihood that a female buffalo aged } \geq 16 \mathrm{yr} \text { bears a female } \\
\text { calf }\end{array}$ \\
\hline \multicolumn{5}{|l|}{ Survival } \\
\hline Calf & 0.73 & 0.73 & $\dagger$ & likelihood that a newborn calf survives to age $6 \mathrm{mo}$ \\
\hline Juvenile & 0.85 & 0.85 & 0.3640 & $\begin{array}{l}\text { likelihood of a juvenile buffalo aged } 0.5-4.5 \mathrm{yr} \text { surviving to the } \\
\text { next year }\end{array}$ \\
\hline Adult & 0.97 & 0.86 & 0.5109 & likelihood of a buffalo aged $4.5-15.5 \mathrm{yr}$ surviving to the next year \\
\hline Senescent & 0.74 & 0.63 & 0.0339 & $\begin{array}{l}\text { likelihood of a geriatric buffalo aged } \geq 16 \mathrm{yr} \text { surviving to the next } \\
\text { year }\end{array}$ \\
\hline
\end{tabular}

$\dagger$ Calf survival to 0.5 years is factored into fecundity parameters in the model. Therefore, elasticity to calf survival is included in the elasticity values for fecundity and does not carry its own elasticity.

In animals up to five years old, age can be determined from tooth-emergence patterns, body size, and horn development. These criteria allow sorting immature buffalo into year cohorts (Grimsdell 1973, Sinclair 1977). In adult buffalo we used tooth wear as an indicator of age, by measuring the height of incisor 1 . Incisor-1 height declines by $\sim 1 \mathrm{~mm} / \mathrm{yr}$ in this population (A. E. Jolles, unpublished data). In 2001, pregnancy tests of 285 females were performed rectally by veterinarian Dave Cooper.

The data presented in this paper were collected during the dry seasons of 2000 and 2001. We tested a total of 1180 buffalo for bTB. Tested buffalo were drawn from three distinct subpopulations, centered in different areas of the park, Masinda, Nqumeni, and Manzibomvu sections. In 2000, 257 buffalo were tested for TB in Masinda section, in the southeastern part of the park. In 2001, 254 animals were tested in the centrally located Nqumeni section, 537 were tested in Masinda section, and 132 buffalo were tested in Manzibomvu section in the north of the park. The three 2001 capture sites accessed distinct buffalo subpopulations.

\section{Necropsy methods and disease severity}

Postmortem exams of TB-positive buffalo were conducted by park and State veterinarians on 225 buffalo culled due to positive TB-test results. Lungs, and lymph nodes of the head and respiratory system, as well as prescapular lymph nodes and the body cavity were checked for macroscopic TB lesions. In a subset of cases, Mycobacterium bovis was grown in culture to confirm pathogen identity and infection status. Each examined organ was rated for TB severity on a scale of $0-4$, with 0 indicating that no lesions were found, 4 indicating that half or more of the organ was filled with TB lesions, and severity classes inbetween these extremes indicating intermediate numbers and sizes of lesions. An overall disease-severity rating was derived from the combined ratings for all organs. Buffalo with the highest severity rating of 4 overall were those that the veterinarians judged would have died from TB within a year. This judgement was based on the majority of at least one lung lobe being occupied by TB lesions, severely impairing respiratory function. In addition, class- 4 cases were always characterized by large TB lesions that were widespread throughout the body, strongly suggesting that the animal was not able to control the progression of lesions at that stage.

\section{Modeling approach}

We used an age-structured matrix population model to translate TB impacts on vital rates to disease effects on population growth rate and age structure. The population growth rate, $\lambda$, is given by the dominant eigenvalue of the Leslie projection matrix; the stable age distribution is given by the corresponding eigenvector, scaled to add up to 1 (Caswell 2001).

Age-specific mortality rates for healthy buffalo were derived from the age structure of herds with very low TB prevalence ( $<10 \%$; average herd pervalence $5.5 \%)$; fecundity rates for healthy cows are based on pregnancy tests of TB-negative animals only (Jolles 2004). To obtain vital-rate parameters for infected animals, we adjusted these baseline parameters according to the estimates of disease effects detailed in this paper (Table 1). Population-wide parameters were then obtained by weighting healthy and infected vital-rate parameters according to disease prevalence. We treat the distribution of infection across different age classes as independent of herd TB prevalence. The available data from high- and low-prevalence herds support this assumption: In our model, TB affects vital rates of buffalo 
aged $4.5 \mathrm{yr}$ and older. For these age classes, age-specific TB prevalence is a linear function of herd TB prevalence (Appendix A).

To evaluate the effects of chronic disease on population growth rate and age structure in the general case, we used the same basic projection matrix as in the model for healthy buffalo above, but allowed the proportionate fecundity and adult survival reduction in infected individuals to vary between 0 and 1 or 0.4 , respectively. Larger survival reductions are not presented here, since, by definition, a chronic disease does not kill most of its hosts quickly. We measured detectability of disease via changes in population age structure as the minimum TB prevalence at which the age structure of an infected population differs significantly from that of a healthy population. Statistical significance was established for each pair of parameter values (fecundity reduction and survival reduction), using chi-square tests, and assuming a sample size of 500 animals each in the modeled healthy and infected populations. We chose this as our reference sample size, because 1000 animals is about the maximum one might catch in the field per capture season. Thus, differences in population age structure that we label "detectable" could indeed be detected in the field, given the best possible capture effort. We programmed our models using Mathematica 5.0 software (2003; Wolfram Research, Champaign, Illinois, USA).

\section{RESULTS}

\section{Effect of TB on mortality}

Our estimate of disease mortality is based on the proportion of TB-positive animals that necropsy revealed to be in critical condition from the disease. Most cases of TB in the buffalo were mild (Fig. 1). Of the infected animals $65-75 \%$ (severity classes 0 and 1 , some in 2) probably showed no clinical symptoms when alive, reflecting the slow progression of this chronic disease. Severe cases of TB that would likely have been fatal within a year were seen in $5 \%$ of TBpositive animals. All were adults, except for one 3-yrold, indicating that disease mortality primarily affects adults. Of infected adults ( $N=92$ individuals), we judged $11 \%$ to have been in critical condition, yielding an estimate of $11 \%$ (95\% confidence interval: [5.3\%, $19.1 \%]$ ) annual mortality from TB.

However, if TB mortalities were concentrated in old, moribund animals, our pathology findings need not indicate higher overall mortality rates: TB might simply be replacing malnutrition or diseases associated with old age as the proximate cause of death. To test this possibility, we examined whether older adults were more likely to be infected with TB than younger adults, and found this not to be the case (see Appendix B: Table B1). Further, among infected adults, we found no evidence that more severe TB infections were concentrated in older adults (see Appendix B: Fig. B1).

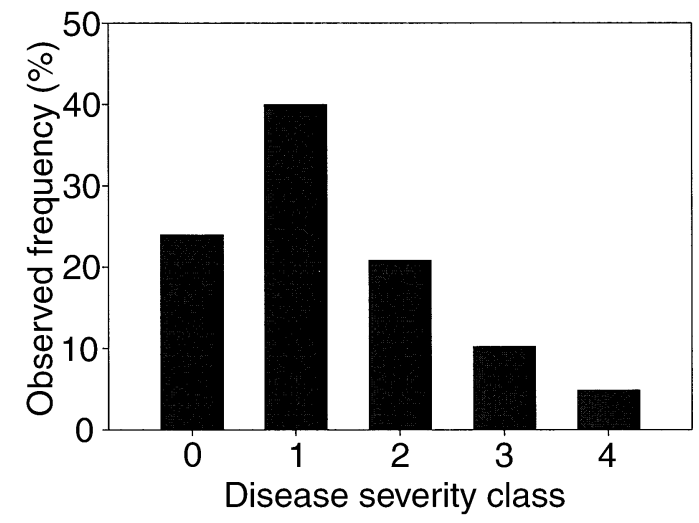

FIG. 1. Disease severity in TB-positive buffalo, all capture sites, year 2001. Disease severity classes are defined as follows: 0, no macroscopic lesions; 4 , imminently fatal; 2 and 3 , intermediate number and size of lesions.

Finally, TB-positive adult buffalo were younger than TB-negative adults from the same herds (Mann-Whitney $U$ test; $\left.N_{\mathrm{TB}-}=187 ; \mathrm{N}_{\mathrm{TB}+}=137 ; P=0.041\right)$, confirming a higher mortality rate in infected animals. The latter data come from herds caught in Masinda section only, because TB prevalence was not high enough in Nqumeni and Manzibomvu sections to yield meaningful sample sizes of TB-positive adults to compare with TB-negative ones. The age pattern is robust to removing all animals that had previously been captured, to control for possible effects of the test-andcull program on adult age distribution (Mann-Whitney $U$ test; $\left.N_{\mathrm{TB}-}=119 ; N_{\mathrm{TB}+}=106 ; P=0.001\right)$. These results corroborate our finding that $\mathrm{TB}$ increases mortality risk in adult buffalo.

\section{Effect of TB on fecundity}

When comparing subpopulations with low $(2.2 \%$, Nqumeni section) and high (53.3\%, Masinda section) TB prevalence in 2001, we observed that the calf:cow ratio appeared higher for the low-prevalence area $\left(\mathrm{N}_{\text {lowTB }}=81\right.$ cows, ratio $=0.64 ; \mathrm{N}_{\text {hightB }}=170$ cows, ratio $=0.52$; chi-square test: $\chi^{2}=3.13 ; P=0.077$ ), suggesting an effect of TB on fecundity. To discover whether there was more direct evidence for a disease effect on fecundity in buffalo, we examined data from 285 females that were tested for both pregnancy and TB infection. We used multiple logistic regression, considering the following factors that might affect pregnancy status: area of origin, month when tested for pregnancy, age, and TB status. Statistically significant effects were found for test month, with more pregnancies detected later in the year when fetuses are of more advanced gestational age $(P<0.001)$; and TB status, with TB-positive females having lower pregnancy rates than uninfected females $(P=0.018$; Appendix C: Table $\mathrm{C} 1$ ). We used late-season pregnancy data (Appendix $\mathrm{C}$ : Table C2) to quantify the reduction in fecundity due to TB. Infection does not appear to affect pregnancy 
TABLE 2. Age distribution of observed and modeled buffalo populations with high and low TB prevalence.

\begin{tabular}{cccccc}
\hline \hline & \multicolumn{2}{c}{$\begin{array}{c}\text { Observed } \\
\text { subpopulations }\end{array}$} & & \multicolumn{2}{c}{ Modeled population } \\
\cline { 2 - 3 } \cline { 5 - 6 } Age $(y r)$ & $<10 \%$ TB $\dagger$ & $53 \%$ TB $\$$ & & $0 \% \mathrm{~TB}$ & $60 \% \mathrm{~TB}$ \\
\hline $0-1$ & 13.7 & 11.6 & & 13.7 & 12.9 \\
$1-5$ & 36.8 & 38.7 & & 34.4 & 35.2 \\
$5-9$ & 18.5 & 16.9 & & 16.0 & 18.0 \\
$9-15$ & 23.5 & 25.3 & & 26.1 & 26.2 \\
$16+$ & 7.5 & 7.5 & & 9.8 & 7.7 \\
\hline
\end{tabular}

Notes: Comparisons between age distributions were made using chi-square tests, assuming a sample size of 500 buffalo for modeled populations. There are no statistically significant differences between any of the population age distributions. $\dagger N=506$ buffalo.

$\ddagger N=498$ buffalo.

rates in young adult females (6-8 yr), but does affect subadults and older adults $(\leq 5.5 \mathrm{yr}$ and $9-16 \mathrm{yr}$ old; $N=60$; chi-square test: $\left.\chi^{2}=5.65 ; P=0.017\right)$. In affected age groups, TB reduced pregnancy rates by $27 \%$ - though this estimate of fecundity reduction due to disease carries substantial uncertainty as a result of the relatively small sample sizes. Senescent females ( $\geq 17 \mathrm{yr} ; N=4$ animals) have been included in this estimate, since there is no a priori reason to expect them to be more resilient to TB than the younger age groups.

\section{Effect of $T B$ on population growth rate and age structure}

Elasticity analysis (Caswell 2001) of the buffalo population model shows that population growth rate responds most sensitively to changes in adult survival, and less to fecundity (Jolles 2004), as is typical of longlived, slow-maturing animals with low fecundity (Heppell et al. 2000). As a result, TB affects population growth rate primarily through reducing adult survival, and to a lesser degree through impairing fecundity. The effects of TB prevalence on growth rate are both direct, in terms of immediate effects on the mean fecundity and survival, and indirect, through shifts in the age structure that would weight some classes more heavily than before. However, because the effects on age structure turn out to be minimal, the primary effects are direct reflections of the per capita losses (fecundity impairment and adult disease mortalities) due to TB. Thus, to a good approximation the growth rate, $\lambda$, decays linearly with disease prevalence $P: \lambda=1.0404-$ $0.0802 \times P / 100$.

In contrast to growth rate, population age structure is not materially affected by TB, either in the data or in the model simulations. This can be seen by comparing the age structures of high $(53 \%)$ and low $(<10 \%)$ TB subpopulations within the park, or by examining the model simulations for uninfected and infected $(60 \%)$ populations (Table 2 ). In the buffalo model, there are a variety of combinations of modified pa- rameters that lead to minimal changes in age structure. In Fig. 2 we plot the minimum disease prevalence needed to cause detectable change in population age structure; the result is an off-center, hump-shaped response surface. The humped part of the response surface defines a range of vital-rate parameter combinations where disease effects on fecundity and survival compensate eachother's impacts on population age structure: moderate $(8-20 \%)$ reductions in survival are hardest to detect in combination with fairly severe (20$60 \%$ ) reductions in fecundity. In other areas of the response surface, compensation is less important. For example, moderate $(<30 \%)$ fecundity reductions on their own do not result in detectable effects on age structure, and survival reductions in excess of $20 \%$ are easy to detect across the whole range of fecundity parameters. The disease-effect parameters observed for $\mathrm{TB}$ in buffalo-a reduction in fecundity by $27 \%$ and adult survival by $11 \%$-fall within the response-surface's peak; that is, these effects on buffalo vital rates compensate each other's impacts on age structure to such an extent that even at $100 \%$ prevalence TB has no significant effect on population age structure.

\section{DiscusSION}

\section{Individual-level effects of $T B$}

Most TB cases in buffalo were mild, with $\sim 70 \%$ of infected animals examined postmortem unlikely to have shown symptoms of disease while alive. This finding is consistent with the expectation that Mycobacterium bovis typically causes chronic infections, which

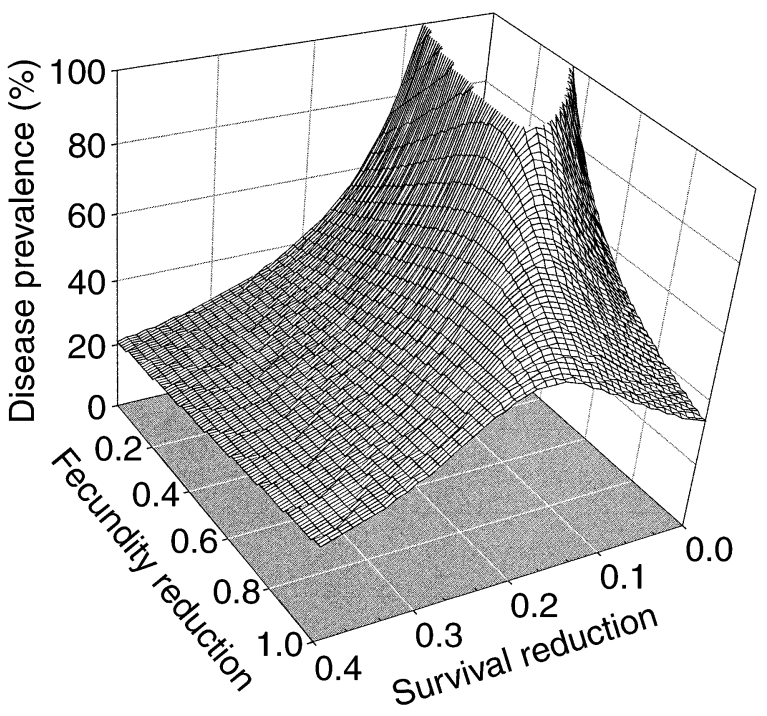

FIG. 2. Response of population age structure to simulated diseases, with varying impacts on adult survival and fecundity. The $x$ - and $y$-axes represent the proportionate reduction in fecundity and survival, respectively, in infected individuals. The $z$-axis denotes the minimum disease prevalence at which the age structure of an infected population differs significantly from that of a healthy population. 
can persist for many years in long-lived hosts before advancing to acute illness. Our estimate of $11 \%$ annual mortality risk due to the disease represents a substantial increase in mortality risk for adult buffalo, given high annual survivorship (95-99\%) in the absence of disease (Sinclair 1977, Jolles 2004): Healthy 5-yr-old buffalo have a life expectancy of an additional 11 years, whereas infected 5-yr-olds may only live for another 6 years, on average, given this estimate of added mortality risk. TB also affected fecundity in buffalo, reducing pregnancy rates in infected females of most age groups by $\sim 27 \%$. There may be an interaction between the effect of TB on pregnancy rates and age of the infected cows. More data will need to be collected to clarify how cow age affects the impact of TB infection on fecundity.

\section{Population-level effects of $T B$}

Our models suggest that population growth rate may be reduced as a result of TB infection in buffalo. The magnitude of this effect scales essentially linearly with TB prevalence in the population. While there is of course some uncertainty in the exact age-specific vital rates for healthy and infected buffalo, which determine model output on population growth rate, these results are qualitatively very robust: TB clearly affects adult survival in buffalo, which is the vital rate that population growth rate is most sensitive to. Under the simple linear model, $\lambda$ drops below 1 at $51 \%$ TB prevalence. However, it should be noted that in reality the threshold disease prevalence for negative population growth is likely to vary with buffalo population size, and will depend on the way in which density dependence and disease effects interact. Since TB only reduces population growth rate below unity at very high prevalences, we would not usually expect to see a population decline due to the disease. However, because of their lower growth rate, infected populations are expected to have difficulty recovering from any additional disturbances that may reduce their numbers. Our field data and model output also show that TB is unlikely to cause detectable changes in buffalo population age structure. The reason is clear from the regression given earlier for growth rate: for the observed elasticities, even a $50 \%$ TB prevalence would result in a shift in abundance of successive age classes of less than $2 \%$, making detection of age-structure shifts problematic. This is compounded by the fact that fecundity impairments due to disease tend to shift the age distribution towards older animals, whereas increased adult mortality counteracts this bias. The main effect of TB on the population is thus a sharp reduction in population resilience.

\section{Conclusions}

TB in buffalo presents a management dilemma: on the one hand, population-level effects of the disease are hard to detect. TB does not cause conspicuous mass mortalities, nor alter population age structure, even at high prevalence. And, in the absence of other distur- bances, TB is unlikely to affect population size. On the other hand, TB does appear to have the potential to reduce population growth rate, and therefore resilience to disturbance, considerably. As a result, TB is unlikely to be identified as a problem for buffalo populations until adverse circumstances reduce population size and a population fails to recover at the rate expected in the absence of disease. At that point, the situation will not be easily mitigated, as controlling diseases is difficult and costly once high prevalences have been reached.

This syndrome of poor detectability coupled with strong effects on population resilience may not be limited to TB, or to buffalo. The characteristics that drive the syndrome-moderate disease impacts on adult mortality and fecundity, host population growth rates that are sensitive to changes in adult survival and not too high in the first place-typify many chronic diseases and large animal hosts. In these systems, typical warning signs that disease is modifying host population dynamics, specifically changes in population size and age structure or sudden mass mortalities, may not be present despite large effects on population growth rate. This has clear implications for wildlife disease management. There appears to be no substitute for monitoring individual-level effects of disease on host vital rates in order to decide, in a timely manner, whether intervention to control a chronic disease is merited.

\section{ACKNOWLEDGMENTS}

Many thanks to our excellent field crew: Shawn Cassatt, Cathy Dora, Alice Henshaw, Zodwa Mnyandu, Thando Nomatshila, Wendy Turner, Matt Waldram, and many shorterterm volunteers. We appreciate the help of Marina Nel, Debbie Cooke, and Alicia and Warren McCall of the State Veterinary Office in Hluhluwe. Capture of buffalo for TB testing was conducted by KZN Wildlife game capture staff, and thanks are due in particular to Paul Jennings and Quentin Rochat. Management staff of HIP, Pete Hartley, Jabulani Ngubane, Paul Havelman, Dave Robertson, and Jeff Cooke ran an efficient buffalo-capture operation, and Dave Balfour, and Ruth and Owen Howison facilitated our work at HIP. We are grateful to Norman Owen-Smith, Han Olff, Andy Dobson, Paul Cross, and Dave Lytle for illuminating discussions on this work. Two anonymous reviewers' suggestions substantially improved the manuscript. This project was supported financially by the National Geographic Society, the Theresa Heinz Foundation, the Wildlife Conservation Society, the Mellon Foundation, the Explorer's Club, and SigmaXi. Anna Jolles had support from Princeton University and a Pew Charitable Trusts Award to S. Levin and D. Rubenstein. Equipment contributions were made by Destron Fearing.

\section{Literature Cited}

Albon, S. D., A. Stien, R. J. Irvine, R. Langvatn, E. Ropstad, and O. Halvorson. 2002. The role of parasites in the dynamics of a reindeer population. Proceedings of the Royal Society of London Series B 269:1625-1632.

Altizer, S., C. D. Harvell, and E. Friedle. 2003. Rapid evoutionary dynamics and disease threats to biodiversity. Trends in Ecology and Evolution 18:589-596.

Ameni, G., H. Miorner, F. Roger, and M. Tibbo. 2000. Comparison between comparative tuberculin and gamma-interferon tests for the diagnosis of bovine tuberculosis in Ethiopia. Tropical Animal Health \& Production 32:267-276.

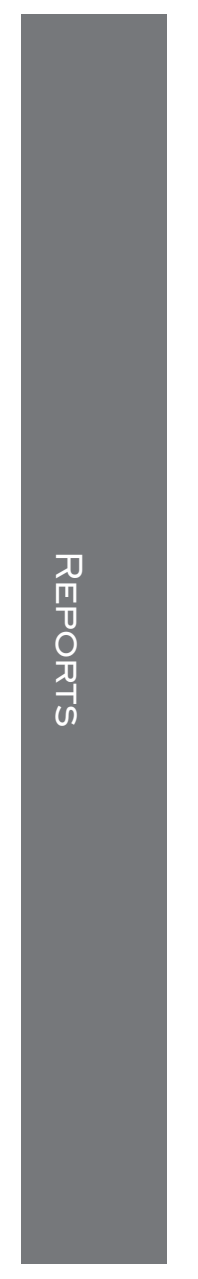


Berger, L., et al. 1998. Chytridiomycosis causes amphibian mortality associated with population declines in the rain forests of Australia and Central America. Proceedings of the National Academy (USA) 95:9031-9036.

Caley, P., and J. Hone. 2004. Disease transmission between and within species, and the implications for disease control. Journal of Applied Ecology 41:94-104.

Caswell, H. 2001. Matrix population models:construction, analysis and interpretation. Sinauer Associates, Sunderland, Massachusetts, USA.

Daszak, P., A. A. Cunningham, and A. D. Hyatt. 2000. Emerging infectious diseases of wildlife-threats to biodiversity and human health. Science 287:443-449.

de Lisle, G. W., R. G. Bengis, S. M. Schmitt, and D. J. O'Brien. 2002. Tuberculosis in free-ranging wildlife: detection, diagnosis and management. Revue Scientifique et Technique de 1'Office International des Epizooties 21:317334.

Donnelly, C. A., R. Woodroffe, D. R. Cox, J. Bourne, G. Gettinby, A. M. Le Fevre, J. P. McInerney, and W. I. Morrison. 2003. Impact of localized badger culling on tuberculosis incidence in British cattle. Nature 426:834-837.

Fulford, G. R., M. G. Roberts, and J. A. P. Heesterbeek. 2002. The metapopulation dynamics of an infectious disease: tuberculosis in possums. Theoretical Population Biology 61: $15-29$.

Garnett, B. T., R. J. Delahay, and T. J. Roper. 2002. Use of cattle farm resources by badgers (Meles meles) and risk of bovine tuberculosis (Mycobacterium bovis) transmission to cattle. Proceedings of the Royal Society of London Series B 269:1487-1491.

Gog, J., R. Woodroffe, and J. Swinton. 2002. Disease in endangered metapopulations: the importance of alternative hosts. Proceedings of the Royal Society of London Series B 269:671-676.

Grimsdell, J. J. R. 1973. Age determination of the African buffalo, Syncerus caffer Sparrman. East African Wildlife Journal 11:31-54.

Gulland, F. M. D. 1995. Impact of infectious diseases on wild animal populations: a review. Pages 20-51 in B. T. Grenfell and A. P. Dobson, editors. Ecology of infectious diseases in natural populations. Cambridge University Press, Cambridge, UK.

Harvell, C. D., K. Kim, J. M. Burkholder, R. R. Colwell, P. R. Epstein, D. J. Grimes, E. E. Hofmann, E. K. Lipp, A. D. M. E. Osterhaus, R. M. Overstreet, J. W. Porter, G. W. Smith, and G. R. Vasta. 1999. Emerging marine diseasesclimate links and anthropogenic factors. Science 285:15051510.

Harvell, C. D., C. E. Mitchell, J. R. Ward, S. Altizer, A. P. Dobson, R. S. Ostfeld, and M. D. Samuel. 2002. Climate warming and disease risks for terrestrial and marine biota. Science 296:2158-2162.

Heppell, S. S., H. Caswell, and L. B. Crowder. 2000. Life histories and elasticity patterns: perturbation analysis for species with minimal demographic data. Ecology 81:654665.

Jolles, A. E. 2004. Disease ecology of tuberculosis in African buffalo. Dissertation. Princeton University, Princeton, New Jersey, USA.

Lilenbaum, W., E. R. Ribeiro, G. N. Souza, E. C. Moreira, L. S. Fonseca, M. A. S. Ferreira, and J. Schettini. 1999. Evaluation of an ELISA-PPD for the diagnosis of bovine tuberculosis in field trials in Brazil. Research in Veterinary Science 66:191-195.

Llamazares, O. R. G., C. B. Gutierrez Martin, D. Alvarez Nistal, V. A. de la Puente Redondo, L. Dominguez Rodriguez, and E. F. Rodriguez Ferri. 1999. Field evaluation of the single intradermal cervical tuberculin test and the interferon-gamma assay for detection and eradication of bovine tuberculosis in Spain. Veterinary Microbiology 70: 55-66.

Ramsey, D., N. Spencer, P. Caley, M. Efford, K. Hansen, M. Lam, and D. Cooper. 2002. The effects of reducing population density on contact rates between brushtail possums: implications for transmission of bovine tuberculosis. Journal of Applied Ecology 39:806-818.

Rodwell, T. C., I. J. Whyte, and W. M. Boyce. 2001. Evaluation of population effects of bovine tuberculosis in freeranging African buffalo (Syncerus caffer). Journal of Mammalogy 82:231-238.

Sinclair, A. R. E. 1977. The African buffalo. A study of resource limitation of populations. University of Chicago Press, Chicago, Illinois, USA.

Thorne, E. T., and E. S. Williams. 1988. Disease and endangered species: the black-footed ferret as a recent example. Conservation Biology 2:66-74.

Tompkins, D. M., et al. 2002. Parasites and host population dynamics. Pages 45-62 in P. J. Hudson, A. Rizzoli, H. Heesterbeek, and A. Dobson, editors. The ecology of wildlife diseases. Oxford University Press, Oxford, UK.

Tuyttens, F. A. M., R. J. Delahay, D. W. MacDonald, C. L. Cheeseman, B. Long, and C. A. Donnelly. 2000. Spatial perturbation caused by a badger (Meles meles) culling operation: implications for the function of territoriality and the control of bovine tuberculosis (Mycobacterium bovis). Journal of Animal Ecology 69:815-828.

Van Riper, C., III, S. G. van Riper, M. L. Goff, and M. Laird. 1986. The epizootiology and ecological significance of malaria in Hawaiian land birds. Ecological Monographs 56: $327-344$

\section{APPENDIX A}

Data supporting the assumption that the distribution of TB infection across age classes is independent of herd TB prevalence are available in ESA's Electronic Data Archive: Ecological Archives E086-124-A1.

\section{APPENDIX B}

Data corroborating mortality effects of bovine TB in adult African buffalo are avilable in ESA's Electronic Data Archive: Ecological Archives E086-124-A2.

\section{APPENDIX C}

Data on bovine-TB effects on fecundity in African buffalo are available in ESA's Ecological Data Archive: Ecological Archives E086-124-A3. 